\title{
Propostas para uma Abordagem Analógica da Música e da Literatura dos Séculos XVII e XVIII: Pressupostos Teóricos
}

Proposals for an Analogical Approach of Music and Literature of XVIIth and XVIIIth Centuries: Theoretical Assumptions

por Moacyr Laterza Filho

\section{RESUMO}

Neste artigo, procuram-se lançar alguns pressupostos teóricos fundamentais para uma abordagem analógica da música e da literatura dos séculos XVII e XVIII. Assim, partindo-se do princípio de que se pode observar a música também em uma dimensão linguística, procura-se observar como isso a aproxima, nesse período, por um lado, das teorias retóricas e, por outro, da concepção cartesiana das Paixões da Alma. Essa aproximação transfigurar-se-á, na música dessa época, naquilo que ordinariamente se chama Doutrina dos Afetos que, por sua vez, crê-se ser um de seus marcos distintivos, revelador de uma mentalidade também social.

Palavras-chave: Música dos Séculos XVII e XVIII; Retórica; Paixões da Alma; Teoria dos Afetos

\section{ABSTRACT}

In this article we seek to lay some fundamental theoretical assumptions for an analogical approach of music and literature of the XVIIth and XVIIIth centuries. Thus, from the starting point that it is possible to observe music also in a linguistic dimension, we try to observe how this relates, in that time, on the one hand to rhetoric theories and, on the other hand, to the Cartesian conception of Passions of the Soul. This relation will become in the music of XVIIth and XVIIIth centuries that commonly called Doctrine of the Affections, which is believed to be one of its distinctive traces, which will reveal also a social mentality.

Keywords: Music of XVIIth and XVIIIth centuries; Rhetoric; Passions of the Soul; Doctrine of the Affections. 


\section{Propostas para uma Abordagem Analógica da Música e da Literatura dos Séculos XVII e XVIII: Pressupostos Teóricos}

If music and sweet poetry agree, As they must needs, the sister and the brother, Then must the love be great 'twixt thee and me, Because thou lov'st the one, and I the other.

(Shakespeare: The Passionate Pilgrim)

Nos estudos que tratam da música dos séculos XVII e XVIII, não é incomum procurar-se estabelecer uma relação bem próxima entre o discurso verbal e 0 "discurso musical", especialmente quando se trata da música vocal, em suas mais diferentes manifestações. Nesses casos, é frequente a tentativa de explicitar e demonstrar, de alguma maneira, a música numa dinâmica de "ilustração" de determinado aspecto do texto poético. A interação entre linguagem musical e linguagem verbal é tomada, assim, como um processo em que o "texto musical" poria em evidência algum "afeto" específico que 0 texto poético pretendesse veicular.

Embora legítima e constituinte de dado importante e observável (de grande riqueza analítica) na música dessa época, essa forma de aproximação limita, desta, um aspecto muito mais amplo e muito mais importante, que a aproxima mais estreitamente da poesia e da prosa que the são contemporâneas. Esse aspecto, observável apenas por um processo analógico, guarda as especificidades de ambos os sistemas linguísticos. Dessa forma, cada um à sua maneira, seria capaz de expressar de forma semelhante uma determinada "mensagem" estabelecida em um sistema comunicativo específico.

Cremos ser, nesse sentido, mais abrangente a correlação entre a música e a literatura dos séculos XVII e XVIII. Se fundamentada na analogia, essa correlação não seria tomada como correspondência biunívoca, mas como a coincidência de aspectos ou funções que certos elementos de linguagem desempenham, guardadas as suas especificidades, em seu próprio sistema linguístico. Uma correlação que, segundo Ferrater Mora (1951), evidencia "uma relação entre sistemas de conceitos homólogos que pode dar lugar a uma diferença ou a uma coincidência" ( $p$. 54. Tradução nossa). Na analogia, assim, de acordo com esse autor, há "o sentido da semelhança de uma coisa com outra, da coincidência de certos caracteres ou funções com outros" (p. 53). Por isso mesmo, essa forma analógica de comparação, que vai do particular para o particular, não tem uma força comprobatória totalmente concludente, mas sim, verossímil ou provável (cf. FERRATER MORA, op. cit.).

Disso deriva um problema. Suponhamos o seguinte: em primeiro lugar, consideremos que as várias artes podem ser entendidas como linguagens diferentes, mas que se prestam a transmitir "mensagens" semelhantes, marcadas pela impossibilidade de verbalização, ainda que se possa usar a palavra por instrumento. Em segundo lugar, consideremos que a transmissão dessas "mensagens" se dê num processo de comunicação semelhante para todas as diferentes formas de manifestação artística. Dessas suposições, nasce a grande indagação: poderia um tipo de arte falar de outro?

Com efeito, essa é uma discussão que não deixa de estar presente em qualquer tipo de reflexão sobre a linguagem. Em se tratando de reflexões sobre a obra de arte, a problemática se acirra e vem indelevelmente à tona quando se a observa sob o prisma da comunicação. Que se dirá, então, quando se trata de um objeto por um lado dotado 


\title{
Propostas para uma Abordagem Analógica da Música e da Literatura dos Séculos XVII e XVIII: Pressupostos Teóricos
}

de uma abstração estrutural quase matemática e, por outro, indissociável, em qualquer grau, da matéria quase bruta que a constitui, como é o caso da música?! Tal dificuldade é que leva, certamente, E. T. A. Hoffmann a dizer o seguinte, num comentário sobre a Kreisleriana de Schumann (apud SCHAEFFER, 1966. P. 09. A tradução é nossa):

\begin{abstract}
Nosso reino não é deste mundo, dizem os músicos, pois onde é que podemos encontrar, na natureza, como o pintor e o escultor, o protótipo de nossa arte?... O som está por toda parte; mas os sons, quero dizer, as melodias que falam a língua superior do reino dos espíritos, não repousam em outro lugar além do seio do homem. No entanto, o espírito da música, semelhante ao espírito do som, não abarca, ele mesmo, toda a natureza? o corpo sonoro, tocado mecanicamente, desperta para a vida, manifesta a sua existência, ou, antes, sua organização, e alcança, então, a nossa consciência. (...) Assim, essas inspirações repentinas do músico, o nascimento, nele, das melodias, seriam a percepção, a concepção inconsciente, ou, antes, inexprimível pela linguagem, da música secreta da natureza, considerada como princípio de vida ou de toda atividade vital.
\end{abstract}

Se pudermos abstrair certos arroubos do Romantismo Alemão ali presentes, depreendemos, desse comentário de Hoffmann, alguns pontos fundamentais da problemática a que nos referimos antes. Não apenas emergem as questões sobre a natureza da matéria de que é constituída a música, mas também, mais interessante, sobre um seu aspecto lingüístico, que, de acordo com esse autor, exprime o inexprimível. Dos Gregos ao século XIX, e além dele, durante todo o século XX, essa discussão rasga a história ocidental e parece sempre esbarrar e empacar num determinado ponto, do qual não se consegue afastar: é música linguagem? 0 que expressa a música? Qual é o nível cognitivo que ela atinge? Ou, ainda, de que nível cognitivo ela se origina? Com sua abstração, e através dela, de que "fala" a música? Ou, antes, a música fala?

Essa problemática nos interessa na medida em que pode orientar a observação das "auto-representações" de uma certa consciência coletiva, num recorte temporal específico. Com isso queremos dizer que o ângulo de visão que se thes dá em diferentes momentos, inclusive temporais, talvez pudesse revelar um pouco da face de quem vê. Se temos interesse em observar os séculos XVII e XVIII num diálogo entre duas formas de expressão artística, uma delas a música, observar a perspectiva do homem dessa época acerca dessa problemática poderia ser, até certo ponto, observá-lo.

No entanto, antes que se entre num ponto de vista específico, é mister que se apresentem alguns tópicos centrais dessa questão, em caráter mais geral. Para tanto, vamos nos apoiar no que diz Pierre Schaeffer (op. cit), que, discutindo a então "nova" música do Século XX, aborda grande parte desses questionamentos. Num grande ensaio talvez mais voltado para a prática musical que para a reflexão pura sobre música (como, em geral, são feitos os trabalhos destinados aos músicos), o grande interesse que desperta o "Traité des Objets Musicaux" encontra-se justamente na sua fundamentação teórica extra-musical, de Saussure a Lévi-Strauss, passando por outros autores importantes, tais como Jakobson.

Schaeffer inicia sua discussão partindo justamente da ideia de que a música pode também ser vista como uma espécie de "documento", no sentido de uma certa auto-repre- 


\section{Propostas para uma Abordagem Analógica da Música e da Literatura dos Séculos XVII e XVIII: Pressupostos Teóricos}

sentação social, como o também afirma Jacques Le Goff (cf. LE GOFF, 1994), não apenas sob uma perspectiva histórica (como é a trabalhada por este autor), mas mesmo sob uma perspectiva antropológica. Citando Lévi-Strauss, Schaeffer chama a atenção para a possibilidade de se poder perceber, tanto no pensamento mítico quanto no científico, um mesmo substrato lógico, comum a ambos. Nessa perspectiva, a música poderia oferecer uma "ocasião singularmente original de pesquisa e de verificação" (SCHAEFFER, op. cit. p. 10). Falando da música do século XX, ele sugere que, dessa forma, a evolução musical poderia estar ligada também ao progresso científico, na medida em que recebe seus meios da acústica (e, em casos então recentes, da eletrônica e da eletro-acústica), mas, é através dos "objetos sonoros" que se torna possível encontrar-se, nela, "as estruturas permanentes do pensamento e da sensibilidade humana" (idem, ibidem). Põe-se em evidência, assim, uma complementaridade entre "meios dados naturalmente e estruturas culturais" (idem, ibidem). Essa mesma complementaridade gera oposições que, segundo Schaeffer, seriam puramente superficiais: antigo e moderno, arte e ciência, sonoro e musical, ou, retomando a linguagem romântica de Hoffmann, espírito e natureza.

A partir desse pressuposto, o Schaeffer faz uma longa reflexão sobre a matéria-prima da música, isto é, o som, e a própria música tomada como sistema. Fazendo uma analogia sistemática entre os elementos da música e os elementos da linguagem, comparando, por exemplo, a nota ao fonema, estruturas musicais maiores a construções sintáticas, Schaeffer não deixa de pôr em evidência a fragilidade de uma tal comparação. A ideia de que a música ocidental apresenta-se indissociável de uma teoria da música perde muito da sua solidez, com a "revolução musical" que irrompe a partir do século XX, quando o sistema artificial de arquétipos rítmicos e de sons pré-determinados não são mais bastantes para as novas formas de expressão musical. No entanto, não deixa de ser importante, para nós, essa ideia tradicional, que não raro associa língua e música, uma vez que o nosso foco central se direciona para os séculos XVII e XVIII. Schaeffer vai muito mais além, apesar disso, e mostra que essa analogia pode ser possível, mesmo fora daqueles padrões tradicionais.

Quando fala, por exemplo, da Música Serial, ele afirma que "uma música nova não é feita para agradar, nem para comover, nem para ser compreendida de imediato. Ela será pouco a pouco compreendida, pelo aprendizado da língua assim forjada. Ela agradará àqueles que tiverem o trabalho de compreendê-la" (op. cit. p.21). Importante essa afirmação, que será endossada mais tarde pelo próprio Schaeffer, pois põe em relevo um aspecto essencial da música, seja ela nova ou não, e que a aproxima de um certo grau lingüístico: ela deve ser inteligível! Dessa forma, ela deve se organizar como sistema, e aquilo que lhe atribui a inteligibilidade não são exatamente os elementos sonoros que a compõem (sejam eles os 12 sons de altura definida do sistema ocidental tradicional, ou, por exemplo, os sons "cultivados" em laboratório pela música eletro-acústica), mas a própria organização desses elementos: a sua estrutura. Há, portanto, segundo Schaeffer uma correspondência apenas longínqua entre a música e a acústica.

Existe, no entanto, um problema substancial que se impõe nessa analogia entre música e linguagem: "toda música é feita para ser ouvida" (idem. p. 133) e, dessa forma, toda linguagem musical só poderia ser possível se atrelada a "valores elaborados no nível da percepção" (idem, ibidem). É claro que um músico hábil poderia analisar uma obra 


\section{Propostas para uma Abordagem Analógica da Música e da Literatura dos Séculos XVII e XVIII: Pressupostos Teóricos}

pelos seus mecanismos internos, pela sua elaboração própria. Nisso há um grau de abstração que não depende necessariamente da execução dessa obra. No entanto, "a análise da música em estruturas abstratas, quer dizer, em termos significativos para 0 intelecto e não para a percepção" (idem, ibidem) só pode ter sentido, segundo Schaeffer, na medida em que constituem "experiências para o ouvir". A análise, assim, pode evidenciar ou talvez traduzir esses aspectos abstratos, mas não os pode determinar, já que o sentido desses mesmos aspectos se constitui em sua manifestação sonora'.

Dessa maneira, a música não pode ser dissociada, em nenhum grau, de sua função comunicativa. Considerada, assim, como instrumento de comunicação, torna-se difícil, na praxis musical, separar o objeto percebido (como unidade intencional) da estrutura a que ele responde, que, por sua vez, está ligada diretamente à experiência perceptiva. Talvez por isso mesmo se possa falar mais de um "sentido" que de "significados" para a música. Para a percepção desse sentido, para procurar indícios dele, diz Schaeffer, é necessário buscar "a consideração de suas estruturas, o problema da delimitação das suas unidades" (op. cit. p. 284).

Fazendo um paralelo bem próximo entre as unidades sonoras da música e as da linguagem, Schaeffer chega com uma certa tranqüilidade à noção de "signo musical", mas marca com cuidado distinto que "a evidente diferença, tão freqüentemente apontada, entre linguagem e música [reside em que] uma é voltada para a compreensão de signos arbitrários e a outra, para o reconhecimento de signos ligados necessariamente ao objeto" (idem, p. 308). Ele muda, assim o conceito saussuriano de signo, ao aplicá-lo à música, e afirma que:

é evidentemente também no nível superior, assim como a língua, que a música adquire todo o seu sentido: na combinação dos objetos de valor. (...) As combinações desses objetos postulam evidentemente uma consciência musical coletiva. As relações mais ou menos necessárias entre as combinações de objetos e as propriedades de um campo perceptivo musical, próprio ao homem, aparecem de agora em diante, como o problema essencial da música" (idem, p. 311. Grifos do autor).

É a partir dessa ideia de consciência coletiva que gostaríamos, de propor o caminho a que nos referimos no início deste artigo. Tomando o que diz Schaeffer e ousando acrescer um outro aspecto ao "objeto musical" a que ele nos remete, não seria incoerente afirmar que a estrutura a que se refere esse autor baseou-se enormemente em elementos conectados, de alguma forma, a uma "teoria da música", como ele mesmo diz, referindo-se ao músico tradicional. Note-se que não se trata de negar essa concepção estrutural da música, mas de observá-la em funcionamento num determinado recorte temporal.

Por sua própria natureza, nos mostra Schaeffer, a música não pode, a menos que de maneira sui generis, ser abordada pela noção de mimese. Isso é o que nos ensina

1 Seria de se perguntar, por exemplo, com isso, como é que Beethoven, completamente surdo, chega à elaboração de um "signo musical" como a Nona Sinfonia, op. 125. Schaeffer não ignora nem nega um certo grau de abstração, presente tanto na música, quanto em toda linguagem. Ele tão somente põe em relevo - e aponta como dado principal - o aspecto da comunicação, e nisso talvez esteja seu grande mérito: ninguém se comunica em gramática pura. 


\section{Propostas para uma Abordagem Analógica da Música e da Literatura dos Séculos XVII e XVIII: Pressupostos Teóricos}

também W. Jaeger (1967), ao falar do ideal platônico de educação: “Platão exige que se comece pela formação da alma, quer dizer, pela música. No sentido amplo da palavra grega, esta não abarca só aquilo que se refere ao tom e ao ritmo, mas também - e, segundo a acentuação platônica, inclusive em primeiro lugar - a palavra falada, o logos" (p. 603 - 604. A tradução é nossa).

Segundo Jaeger, Platão reconhece a primazia da música sobre as outras artes, afirmada pela tradição. Não sem antes discutir a legitimidade disso, ele chega à conclusão de que essa primazia é perfeitamente justificada, já que "o ritmo e a harmonia são os que mais fundo penetram no interior da alma, e os que com mais força se apoderam dela, infundindo-lhe e comunicando-lhe uma atitude nobre" (idem, p. 626).

Além disso, a música educa o homem para perceber "com uma precisão incomparável o que há de exato ou de defeituoso em uma obra de beleza e em sua execução". Uma pessoa assim educada, "sente desenvolver-se, dentro de si, desde a sua juventude e em uma fase inconsciente, portanto, de evolução, uma segurança infalível de gosto pelo belo e ódio ao feio, que mais tarde a capacita para saudar, com alegria, como algo afim a ela, o conhecimento consciente, se este se apresenta" (idem, ibidem). 0 ideal platônico de conhecimento, diz Jaeger, é um processo gradual que vai se desenvolvendo ao longo da vida e que "faz com que a alma se pareça cada vez mais com a essência dos valores que aspira a conhecer" (idem, p. 624). Segue Jaeger:

0 bem não pode ser concebido como algo formalmente conceitual situado fora de
nós, sem que de antemão tenhamos participado previamente de sua natureza; o
conhecimento do bem se desenvolve no homem na medida em que se vai fazendo
realidade e vai tomando forma nele mesmo. Portanto, para Platão, o caminho que
conduz à educação dos olhos da inteligência é o da educação do caráter, a qual, sem
que o homem tenha consciência disso, modifica a sua natureza de tal modo, pela
ação das forças espirituais mais vigorosas (a poesia, a harmonia e o ritmo), que por
fim lhe é dado alcançar o princípio supremo através de um processo que o vai apro-
ximando de sua mesma essência. (...) Só temos uma cultura 'música', no sentido
pleno do vocábulo, quando sabemos perceber e apreciar devidamente, sempre e em
todas as suas manifestações, no pequeno e no grande, as 'formas' do domínio de si
mesmo e da prudência, da valentia e da generosidade, da distinção e de tudo que com
ela se relaciona, da mesma forma que suas manifestações reflexas (op. cit. p. 624).

Indo mais além, vemos, com Roland de Candé (1994, p. 71-75), que, na Antiguidade Clássica, a música era tida como "expressão sensível das relações matemáticas que regem o mundo" e, assim, intermediária entre a harmonia universal e a alma humana. Ela se coloca aí através de uma mimese muito particular: ela imita "as ideias, as ações e a ordem das coisas". Assim, ela é meio imediato para o conhecimento do bem e do mal.

Citando Damon de Atenas, cuja influência, no plano da "filosofia musical", se estende, segundo Candé, até pelo menos os discípulos de Aristóteles, o historiador e musicólogo francês comenta:

Mas como a música pode servir de intermediária entre a ordem natural e a alma humana? Pela mimesis, responde Damon: a arte é imitação, e a alma imita, por sua 


\title{
Propostas para uma Abordagem Analógica da Música e da Literatura dos Séculos XVII e XVIII: Pressupostos Teóricos
}

\author{
vez, os simulacros da arte. Ora, em música os modelos não são objetos, mas ideias, \\ ações e a ordem das coisas. Portanto, pode-se imitar tanto o bem como o mal; isso \\ é um perigo para o Estado, que deve zelar pela qualidade da educação (idem, p. 73).
}

Note-se que esbarramos mais uma vez em uma aproximação entre música e linguagem. Se, pela mimese, ela é intermediária nessa dinâmica do conhecimento do bem e do mal, ela precisa funcionar como significante (no sentido linguístico do termo) num processo de comunicação. Pode-se ir, no entanto, mais além dessa ideia: se ela pode ter valor e função de significante, a noção de signo musical, como já aprendemos com Schaeffer, difere da noção saussuriana, na medida em que ela é necessária e indissociavelmente ligada ao seu objeto concreto. Assim, ele passa a não fazer referência à realidade que lhe é exterior, apesar de ser, segundo a concepção platônica apontada por Jaeger, força vigorosa para a transformação da alma do homem e, portanto, meio inconteste de conhecimento. Baseando-se, como a matemática, "num sistema de símbolos operacionais, que designam operações, não objetos ou ideias", quando inserida num processo de comunicação, a música "significa a si mesma", segundo Nicolas Ruwet (apud CANDÉ, op. cit. p. 11. Grifos do autor), e é, para que a comunicação se dê, "coletivamente interpretável".

Interessa-nos sobremaneira a associação dessa função mimética da música com a sua necessária "autonomia linguística". Voltando ao que propusemos no início deste artigo, poderíamos dizer que, se quisermos tentar verificar até que ponto a música pode funcionar, intertextual e metalinguisticamente, como "instrumento de observação" de outra forma de manifestação artística qualquer (no nosso caso, nomeadamente a literatura), é necessário que a entendamos como linguagem suficientemente autônoma. Por outro lado, se quisermos mergulhar no desejo que regia o músico dos séculos XVII e XVIII de ser a música o veículo mais puro para despertar as paixões humanas (o que bem poderia ser uma espécie de leitura "moderna" dos ideais platônicos a que nos referimos antes), seria imprescindível voltarmo-nos para a ideia que propõe a música como mimese, imitadora daquelas mesmas paixões, idealizadas.

É no sentido cartesiano que o conceito de "paixão" se apresenta para o homem dos Séculos XVII e XVIII e são essas as paixões, tais como as observou Descartes, que tanto o músico quanto o orador dessa época procuravam despertar em sua audiência, cada qual com seu discurso. Dada a exiguidade de nosso espaço, damo-nos a liberdade de nos basearmos principalmente no comentário que faz Émile Bréhier (1948. vol II) sobre a obra de Descartes.

Na concepção cartesiana, diz Bréhier, "o homem se define, em primeiro lugar, a título de substância pensante e espiritual; porém a sensação, a paixão, a vontade são, para Descartes, modos de pensamento" (op. cit. p. 104. A tradução é nossa). Há, segundo o pensador do Século XVII, dois grupos de pensamento: as paixões e as ações. Aquelas seriam, de modo geral, "tudo o que é dado ao pensamento sem que ele atue, quer dizer, tanto as noções claras e distintas do entendimento (extensão ou pensamento e os axiomas primeiros), quanto as paixões propriamente ditas: cólera ou desejo" (idem, ibidem). Ação, por sua vez, designa uma capacidade de julgamento (ou de abstenção de julgamento), regida por uma vontade livre, que possibilita ao homem dar ou negar 


\section{Propostas para uma Abordagem Analógica da Música e da Literatura dos Séculos XVII e XVIII: Pressupostos Teóricos}

a sua adesão aos "enlaces de idéias apresentados pela imaginação, pelo entendimento ou pelos sentidos" (idem, ibidem). Essa liberdade infinita da vontade está presente, segundo Bréhier, em toda a filosofia cartesiana.

Essa concepção de homem ("substância pensante e espiritual") gera uma noção importante no pensamento de Descartes. 0 homem é mais do que corpo e alma, embora seja ambos: a alma está unida ao corpo em laço tão firme e íntimo, que o composto é uma unidade em si. Essa união consiste de certas interações: a ação do corpo sobre a alma, na sensação e na paixão, e a ação da alma sobre o corpo, no ato voluntário. Essa união, para Descartes, é natural e escapa totalmente ao conhecimento da alma que, ao experimentar a paixão, "ignora completamente o mecanismo dos espíritos animais que produz nela tal paixão". Além disso, as paixões, não apenas definidas como dependentes de causas corporais, só podem ser inteiramente compreendidas se se pode apreciar sua utilidade, qual seja, "fortificar e fazer durar, nos pensamentos, aquilo que é bom que a alma conserve e que, sem isso, apagar-se-ia facilmente" (idem, p. 106). Visto nessa concepção particular (uma espécie de resultante entre alma e corpo), o homem, mesmo estando sujeito às paixões e às sensações (que chegam àquela através deste), é dono de seus movimentos corporais, e sua felicidade ou desgraça dependem unicamente de suas paixões.

Assim, interessa conhecer a natureza e a utilidade de cada paixão e medir, depois disso, o poder que elas têm sobre a nossa vontade e vice-versa, quer dizer, o poder que a vontade pode exercer sobre as paixões. Estas poderiam ser definidas, na concepção cartesiana, como "afetos ou emoções da alma que se referem especialmente a ela mesma - distinguindo-se, por isso, das sensações, que se referem a objetos exteriores à alma - e que são engendrados, continuados e aumentados por certo movimento de espírito" (BRÉHIER, op. cit. p. 106). Descartes chega a tentar determinar o movimento específico do espírito para cada paixão e o seu efeito em reações orgânicas determinadas, tais como movimentos de cólera, abatimento, lágrimas, diferentes expressões de emoção e assim por diante. Esses movimentos de espírito têm seu ponto de partida geralmente na impressão, sobre os sentidos, de um objeto exterior, ou ao menos na imagem desse objeto. A paixão é, assim, uma atitude passiva da vontade em respeito a esses objetos, sob a ação daquele movimento.

Há cinco paixões primitivas. A primeira e mais fundamental, condição de todas as outras, é a Admiração. Esta é, em Descartes,

uma das formas da atenção espontânea, graças à qual um objeto é posto, de certo modo, em primeiro plano, por causa de sua novidade em relação aos outros. Depois vem o Amor, no qual a vontade está disposta a unir-se ao objeto; o ódio, que dispõe a vontade a rechaçá-lo e o Gozo e a Tristeza, que supõem prévios o Amor e o Ódio, por derivar o Gozo da satisfação das paixões e a Tristeza, de sua contrariedade (idem, p. 107).

Todas as outras paixões não passariam de matizes ou compostos dessas cinco paixões primárias. Segue Bréhier, acerca de Descartes: 


\title{
Propostas para uma Abordagem Analógica da Música e da Literatura dos Séculos XVII e XVIII: Pressupostos Teóricos
}

\begin{abstract}
As paixões, por sua natureza, e previamente a qualquer razão, dispõem nossa vontade para acolher conhecimentos novos (admiração), buscar o que nos é útil (amor) e refutar, pelo contrário, os perigos (ódio). Porém essas disposições contêm também juízos sobre o bem e o mal, juízo que, desde que as paixões permaneçam em seus limites naturais, são verdadeiros; o que sucede raras vezes. Indubitavelmente, 'a utilidade das paixões consiste em que elas fortificam e fazem durar na alma pensamentos que a esta convém conservar' (idem, p. 107 - 108).
\end{abstract}

Assim, pode haver uma certa imperfeição na finalidade das paixões, já que nem tudo que se ama é bom, e nem tudo que se odeia é mau. Mas é justamente sobre essa imperfeição que tem ação a vontade, que acaba exercendo sobre elas um domínio soberano,

seja fixando a atenção do ânimo sobre os objetos contrários aos que produzem as paixões que se quer destruir, seja aproveitando as associações entre nossas idéias para fazer mudar o objeto de uma paixão, mediante determinada transferência voluntária. Pode-se, mediante hábitos, fazer com que um objeto produza um efeito precisamente inverso ao que naturalmente produz, como se acostuma o cão de caça a deter-se ante uma peça à qual espontaneamente perseguiria. Assim, não se permite subsistir senão as paixões "lícitas", quer dizer, os gozos e os desejos que nos apresentam as coisas como melhores e mais desejáveis do devido (BRÉHIER, op. cit. p.109).

É a partir de uma tal concepção filosófica, associada às funções sociais que a música e outras formas de expressão artística representam nos Séculos XVII e XVIII que surge, na música dessa época, um de seus pontos distintivos mais importantes: 0 que se costumou chamar de Teoria dos Afetos (ou Doutrina dos Afetos, termo que, traduzido da expressão em inglês, nos parece mais apropriado)

Esta tem como um de seus princípios fundamentais o mesmo processo de fragmentação e "cristalização" da linguagem, observado por Cérard Cenette (1972) na poesia barroca. Cada palavra ou cada imagem, nessa poesia, seria dotada de uma "valência" própria, no sentido químico do termo, e, assim atomizada, receberia um específico valor de contraste. Através de reduções bruscas e de uma certa elaboração de clichês, o próprio mundo sensível seria fracionado e cristalizado em sua percepção e, assim "fingido", poderia ser manipulado e reconstruído, sendo passível de compreensão.

Ora, é precisamente esse um dos procedimentos mais fundamentais da Doutrina dos Afetos, quando, por um lado, ela atribui a qualquer elemento constituinte de sua música (do tom escolhido à figura rítmica utilizada) um significado específico, não raro relacionado a figuras pré-estabelecidas da Retórica Clássica. Por outro lado, isso também assim é quando se atribui a um ou a outro desses elementos o poder específico de despertar ou "adormecer" uma determinada paixão.

0 músico dos Séculos XVII e XVIII, através dela, rompe com o status inabalável que a música adquire, na Idade Média, ao ser posta ao lado das Matemáticas e da Astronomia, no quadrivium das sete Artes Liberais. Assim, a música é forçada a adotar novos valores teóricos, que procuram uma outra forma de expressão (musical), comparável e associada aos ideais de uma Teoria Retórica que, vinda dos Clássicos Gregos, parece ter 


\section{Propostas para uma Abordagem Analógica da Música e da Literatura dos Séculos XVII e XVIII: Pressupostos Teóricos}

chegado ao homem da Renascença, via Idade Média, através dos autores latinos, tais como Cícero e Quintiliano. Se essa nova ideia de música começa a ser abraçada ainda na Renascença, é no período seguinte que ela se afirma.

A música, portanto, é deslocada de sua identidade com as Matemáticas e, deixando a companhia delas e a da Astronomia, é posta, então, ao lado da Arte Retórica. É através da Doutrina dos Afetos que se pode notar essa aproximação e ela seria, assim, fundamental para o reconhecimento distintivo da música dos Séculos XVII e XVIII. Dessa forma, se cabia ao orador direcionar e, em certo sentido, "manipular" as reações de sua audiência, sendo, para tanto, capaz de atingir-lhe as paixões, também ao músico deveria caber fazê-lo.

Isso é o que mostra, por exemplo, Johann Joachin Quantz (1966), em seu tratado sobre a arte de se tocar flauta (Versuch einer Anweisung die Flöte traversiere zu spielen), cuja primeira publicação data de 1752:

A execução musical pode ser comparada à elocução de um orador. o orador e
o músico têm, em última análise, o mesmo objetivo, seja quanto à prepara-
ção de suas produções, seja quanto à execução final delas: quer dizer, tan-
to o músico quanto o orador devem fazer de si próprios mestres dos corações
de seus ouvintes, devem despertar-lhes ou acalmar-lhes as paixões e trans-
portá-los ora a este sentimento, ora àquele. Assim, é vantajoso a ambos que
cada um tenha conhecimento do ofício do outro ( $p$. 119. A tradução é nossa).

Um pouco antes de Quantz, François Couperin (1961) escrevia despreocupadamente em L'Art de Toucher le Clavecin (publicado pela primeira vez em 1716 e depois republicado, com revisões, no ano seguinte): "assim como há uma grande distância da Gramática à Declamação, há também um infinito entre a tablatura e a maneira de se tocar bem" ( $p$. 9. A tradução é nossa).

Bastam-nos apenas essas passagens para mostrar como, nos Séculos XVII e XVIII, a aproximação entre os procedimentos musicais e os procedimentos da oratória era uma espécie de consenso e, mais do que isso, arriscamos dizer, uma mentalidade: uma espécie de imaginário comum. Couperin nem sequer se dá ao trabalho de explicar a correlação existente entre a música e a teoria da linguagem, sintetizada na Teoria Retórica (e, convém lembrar, a Retórica foi, durante muito tempo a grande e única teoria da linguagem - Cf. CURTIUS, 1957), tamanha era a clareza de que essa relação definitivamente havia. Quantz (op. cit), por sua vez, chega a definir a música como "nada mais do que uma linguagem artificial", através da qual se procura comunicar ao ouvinte as "ideias musicais" do próprio músico.

Ora, voltamos, aqui, à proposição que fizemos no início deste trabalho: a de uma dupla concepção da música, tomada como linguagem. Por um lado, nota-se, nessa afirmação de Quantz, algo da autonomia linguística a que se refere Schaeffer, em que o signo musical, atrelado necessariamente ao seu objeto, possui um sentido (mais que significados) e é instrumento de comunicação que responde a uma estrutura, que Couperin associa inadvertidamente à Gramática. Por outro lado, nessa aproximação entre a prática musical e a prática oratória, vê-se um pouco da noção mimética da música, que 


\section{Propostas para uma Abordagem Analógica da Música e da Literatura dos Séculos XVII e XVIII: Pressupostos Teóricos}

quer se fazer, à maneira do orador, senhora das paixões de sua audiência: se voltarmos a tomar a noção cartesiana sobre as paixões, talvez pudéssemos ver que o "objeto musical" (para tomar o termo de Schaeffer), tal como era concebido pelo músico dos Séculos XVII e XVIII, poderia ser, ele mesmo, um dos "objetos exteriores", de acordo com Descartes, que lançam sobre os sentidos determinada impressão e que, através deles, fazem despertar as paixões da alma. Ora, esses objetos, a menos a princípio, devem ter certa identidade com as mesmas paixões que provocam e, ainda que elaborados artificialmente, como no caso da música (e das outras artes), poderiam ser concebidos como reflexos ou representações dessas mesmas paixões.

Essas representações, produzidas seja pelo "discurso" musical, seja pelo discurso da oratória, funcionariam, de certa forma, como alegorias das próprias paixões que representam. Elas, assim entendidas, talvez pudessem ser constituídas e percebidas tanto na macro-unidade, na totalidade e integridade de uma obra completa, quanto nas micro-estruturas, nos fragmentos mineralizados, a que se refere Gérard Genette (op. cit), dos artifícios e das figuras de linguagem, ou nas pequenas "estruturas" ou "figuras" musicais (que, para nós, em última instância, teriam a mesma funcionalidade lingüística), dotadas de valência própria e específica. 


\section{Propostas para uma Abordagem Analógica da Música e da Literatura dos Séculos XVII e XVIII: Pressupostos Teóricos}

\section{Referências}

$>$ BARTEL, Dietrich. Musica poetica. Musical-Rhetorical figures in German Baroque music. Lincoln - Londres: University of Nebraska Press, 1998.

> BRÉHIER, Émile. Historia de la Filosofía. vols. 1 e 2. Prólogo de José Ortega y Gasset. Trad. espanhola de Demetrio Náñez. Buenos Aires: Editorial Sudamericana, 1948.

> CANDÉ, Roland de. História universal da música. Trad. Eduardo Brandão. São Paulo: Martins Fontes, 1994.

> COUPERIN, François. L’art de toucher le clavecin. Wiesbaden: Breitkopf đt Härtel, 1961.

> CURTIUS, E. R. Literatura européia e Idade Média Latina. Trad. Teodoro Cabral. Rio de Janeiro: Instituto Nacional do Livro, 1957.

> DESCARTES, René. Obra escolhida. Introdução de Gilles-Gaston Granger. Prefácio e notas de Gérard Lebrun. Trad. J. Guinsburg e Bento Prado Júnior. São Paulo: DIFEL, 1988.

> FERRATER MORA, José. Diccionario de Filosofía. Buenos Aires: Editorial Sudamericana, 1951.

$>$ GENETTE, Gérard. Figuras. Trad. Ivonne Floripes Mantoanelli. São Paulo: Perspectiva, 1972.

$>$ JAEGER, Werner. Paideia: Ios ideales de la cultura griega. Trad. espanhola de Joaquín Xirau e Wenceslao Roces. Cidade do México, Fondo de Cultura Econômica, 1967.

> LE GOFF, Jacques. História e Memória. Trad. Irene Ferreira et al. Campinas: UNICAMP, 1994.

$>$ QUANTZ, Johan Joachin. On playing the flute. Trad. inglesa de Edward R. Reilly. Londres: Faber it Faber, 1966.

> SCHAEFFER, Pierre. Traité des objets musicaux. Paris: Seuil, 1966.

Moacyr Laterza Filho, Pianista e cravista, professor da Universidade do Estado de Minas Gerais e da Fundação de Educação Artística (Belo Horizonte), Mestre em Teoria da Literatura pela UFMG e Doutor em Literatura pela PUCMINAS. moacyrlaterzafilho@gmail.com 